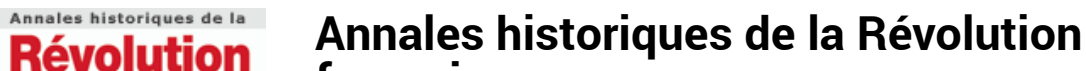

française française

344 | avril-juin 2006

La prise de parole publique des femmes

\section{Cinq figures féminines méconnues du Romantisme allemand}

\section{Marita Gilli}

\section{(2) OpenEdition \\ 9 Journals}

Édition électronique

URL : https://journals.openedition.org/ahrf/6583

DOI : 10.4000/ahrf.6583

ISSN : 1952-403X

Éditeur :

Armand Colin, Société des études robespierristes

Édition imprimée

Date de publication : 1 juin 2006

Pagination : 243-245

ISSN : 0003-4436

Référence électronique

Marita Gilli, «Cinq figures féminines méconnues du Romantisme allemand », Annales historiques de la Révolution française [En ligne], 344 | avril-juin 2006, mis en ligne le 02 juillet 2008, consulté le 24 avril 2022. URL : http://journals.openedition.org/ahrf/6583 ; DOI : https://doi.org/10.4000/ahrf.6583

Ce document a été généré automatiquement le 24 avril 2022.

Tous droits réservés 


\title{
Cinq figures féminines méconnues du Romantisme allemand
}

\author{
Marita Gilli
}

\section{RÉFÉRENCE}

Georges SOLOVIEFF, Cinq figures féminines méconnues du Romantisme allemand, préface de Roland Mortier, Paris, L'harmattan, 2005, 347 p., ISBN 2-7475-8443-7, $31 €$.

1 Les femmes dont il est question dans cet ouvrage ne sont certes pas les premières à avoir voulu s'émanciper, mais l'originalité de la situation en Allemagne au tournant des $\mathrm{XVIII}^{\mathrm{e}}$ et $\mathrm{XIX}^{\mathrm{e}}$ siècles, c'est qu'elles ont vécu dans le sillage d'écrivains célèbres et qu'elles ont été en contact les unes avec les autres.

2 Ce qui les caractérise toutes, c'est leur vie sentimentale riche, car c'est d'abord dans ce domaine qu'elles s'émancipent. Therese Huber qui avait épousé en premières noces le célèbre explorateur G. Forster s'en sépare pour vivre avec leur ami commun L.F. Huber qu'elle épouse après la mort de Forster. Elle a également d'autres amours, en particulier le bibliothécaire F.L.W. Meyer avec lequel elle reste très longtemps en correspondance. Dorothea Schlegel quitte son mari, Simon Veit, un riche négociant avec lequel elle s'ennuie, pour vivre avec Friedrich Schlegel qu'elle finira par épouser. Sophie Mereau divorce et a de nombreuses liaisons avant d'épouser Brentano; c'est sans doute elle qui est la plus consciente de sa spécificité féminine. Helmina von Chezy est une enfant terrible qui a le courage de s'exiler à 17 ans, mène une vie aventureuse, a plusieurs amants et se lance dans une action humanitaire qui lui vaudra parfois d'être rejetée de la société. C'est sans doute la plus moderne par l'affirmation de son indépendance. Souvent mise au ban de la société, Caroline Schelling a plusieurs aventures et deux maris avant de trouver celui avec lequel elle va pouvoir vivre en harmonie. Ces femmes qui se connaissaient par le fait qu'elles gravitaient dans le milieu intellectuel de l'époque - et qui souvent se détestaient, il faut bien le dire - étaient animées d'une même volonté d'émancipation et du même désir de donner un sens à 
leur vie. On peut dire avec Roland Mortier qu'à des degrés divers, elles sont des révoltées en rupture avec leur milieu social d'origine.

Elles ont toutes également participé à la vie intellectuelle de leur époque et écrit. Deux d'entre elles sont de véritables professionnelles qui doivent vivre de leur plume, Therese et Sophie. De leur côté, Dorothea écrit un roman qui fait parler de lui, Florentin, et Helmina des Mémoires qui sont un précieux document de l'époque. Quant à Caroline, elle refuse de publier, mais joue un rôle très important de médiatrice et a une grande influence sur le Romantisme allemand, tout comme Dorothea qui crée un salon. Elles ont joui d'une grande notoriété, étant associées à des hommes célèbres et, excepté Therese qui expose dans le Morgenblatt de 1817 qu'il faut combattre le Romantisme, elles ont participé au développement du romantisme allemand.

Et pourtant, - en raison de la condition féminine de l'époque - elles ont généralement gardé conscience de leur infériorité et sont restées dans l'ombre de leurs conjoints ou compagnons. Caroline se contente d'écrire anonymement pour des revues. Dorothea fait paraitre son roman sous le nom de $\mathrm{F}$. Schlegel et s'associe énormément à ses travaux au point de sacrifier les siens. Le nom de Sophie Mereau qui a tant publié ne sera connu que par association à celui de Brentano. Quant à Therese, elle signe L.F. Huber pendant longtemps et, après la mort de son mari, écrit anonymement jusqu'en 1811. C'est elle qui exprime le mieux ce sentiment persistant d'infériorité en écrivant à son père en 1810: "Pour moi, être imprimée me cause toujours un sentiment d'inquiétude douloureux et humiliant. Cela ne convient pas à une femme ». Pour elle, il est contradictoire d'être femme de Lettres et femme, et c'est en exerçant sa vocation de femme au foyer qu'elle pense avoir acquis le droit d'écrire. En tout cas, elle ne revendique jamais les droits de la femme. Dorothea de son côté garde toujours un sentiment de culpabilité envers F. Schlegel qu'elle adoucit par un dévouement excessif, bien qu'elle ait un caractère très fort et une grande volonté d'indépendance. C'est en raison de cette ambiguïté que la correspondance de ces femmes est particulièrement intéressante, car là, elles peuvent s'épancher librement.

Le mérite de cette publication est donc d'apporter une contribution importante au combat pour l'indépendance de la femme et à ses difficultés et également d'avoir replacé ces personnages dans leur époque aussi bien sur le plan intellectuel qu'historique. En effet, si l'on met à part Therese, elles ont contribué et collaboré à l'élaboration du Romantisme, en particulier dans sa première phase. Pour la plupart, elles ont eu des liens privilégiés avec la France et établi ainsi un lien entre nos deux pays. Elles se sont exprimées sur les événements historiques importants : la Révolution française, les conquêtes de Napoléon, le nationalisme allemand naissant. Les personnalités masculines qu'elles ont côtoyées apparaissent aussi sous un jour peu connu et elles ne se manifestent généralement pas par beaucoup de grandeur...

L'ouvrage comporte, outre la préface de Roland Mortier, d'abondantes notes (que l'on aurait préféré trouver en bas de page ou de façon continue plutôt qu'en fin d'ouvrage regroupées par chapitre), une bibliographie sur chacune ainsi que l'indication des sources. Un index des noms cités complète cet appareil critique. 